\title{
Why Digital Games Can Be Advantageous in Vocabulary Learning
}

\author{
Amin Rasti-Behbahani \\ University of Jyvaskyla, Finland
}

\begin{abstract}
Vocabulary learning is an integral part of language learning; however, it is difficult. Although there are many techniques proposed for vocabulary learning and teaching, researchers still strive to find effective methods. Recently, digital games have shown potentials in enhancing vocabulary acquisition. A majority of studies in digital game-based vocabulary learning (DGBVL) literature investigate the effectiveness of DGBVL tasks. In other words, there are enough answers to what questions in DGBVL literature whereas why questions are rarely answered. Finding such answers help us learn more about the structure of the DGBVL tasks and their effects on vocabulary learning. Hence, to achieve this aim, the available literature on digital games and vocabulary learning were systematically reviewed from 1996 to 2020 . The results revealed seven themes such as motivation, authenticity, repetition, instantiation, dual encoding, interactivity, and feedback. Based on the available literature, these themes are factors, in digital games, that can contribute to enhancing vocabulary acquisition.
\end{abstract}

Index Terms — vocabulary learning, word learning, digital game, digital game-based learning, language learning

\section{INTRODUCTION}

Second or foreign language learners with low vocabulary knowledge are widely reported as communicatively inefficient learners (Kang, 1995). Vocabulary is a collection of words, or units of meaning, that everyone acquires when he or she learns a language (Carter, 1998). However, learning vocabulary is difficult because it is an incremental process; or, word knowledge is a multidimensional knowledge (Ringbom, 1987; Nation, 2001; Schmitt, 2007). In other words, Nation (2001) observes that knowing a word has two modes: receptive or understanding a word when it is read or heard; and productive, or ability to use a word in writing or speaking. Also, he observes that knowing words' form, meaning, and use are other aspects of knowing a word. Hence, for knowing a word, many pieces of interrelated information must be retained by a language learner. Therefore, vocabulary learning is difficult, and somehow impossible in one setting (Ringbom, 1987; Schmitt, 2007). Hence, to teach vocabulary, a comprehensive method of instruction is needed to overcome the complexity of vocabulary acquisition.

In recent years, digital-games have shown potentials in enhancing vocabulary learning. Researchers think that "digital-games are another avenue for experimentation in a safe virtual environment" (Kirriemuir, 2002). DGBVL literature has grown significantly over the past decade. Most studies in the available DGBVL literature report positive effects of the DGBVL tasks on both general and field-specific/technical vocabulary learning (Rankin, Gold, \& Gooch, 2006; Yip \& Kwan 2006; Fotohi-Ghazvini, Earnshaw, Robinson, \& Excell, 2009; deHaan, Reed, \& Kuwada, 2010; Hung, 2011; Jasso 2012; Bakar \& Nosratirad, 2013; Vahadat \& Rasti Behbahani, 2013, Alias, Rosman, Rahman, \& Dewitt, 2015, Chen, Tseng, \& Hsiao, 2018; Zou, Huang, \& Zie, 2019). These studies discuss that DGBVL tasks can offer unique opportunities, which can enhance vocabulary learning more effectively than paper-and-pencil vocabulary learning tasks and techniques.

Although the available DGBVL literature reports about the potential of DGBVL tasks, there are not enough information on how DGBVL tasks can enhance vocabulary learning effectively. Hence, reflecting on Chian-Wen's (2014) statement: "the evolution of research on DGBL in EFL context has reached a stage that" answering the question of "how" and "why" is preferred over "what" (p. 134), in this systematic review of literature, the following question are tried to be answered.

Research Question:

Why can digital games affect vocabulary acquisition effectively and accelerate the incremental process of vocabulary learning?

\section{METHODOLOGY}

To answer the research question, a systematic review of the available DGBVL literature was conducted. To do so, Creswell's five steps for analyzing and reviewing the literature were followed (Creswell, 2012, p. 81).

- Find the important keywords that lead you to the related literature

- Locate the related literature by searching the databases available.

- Evaluate the relevant literature and select among them critically. 
- Take notes, and organize the literature.

- Write your own report.

\section{A. Keywords}

To search the databases, I used five keywords and their combinations. They were: "digital games/video games", "vocabulary", "word", "acquisition/learning", and "language".

\section{B. Locate the Related Literature}

Free software, called Publish or Perish (Harzing, 2012), was used to search through the Google Scholar and JYKDOK, the University of Jyvaskyla library, multi-databases for the English only peer-reviewed papers, between 1996 and 2020.

\section{Selecting Literature Critically}

To evaluate and to decide on the found papers, the steps in the PRISMA flow diagram (Liberati et al., 2009) were followed. First, 763 articles were located. Next, they were sorted them out by relevance in the software. Then, the first 150 papers were screened by considering their titles, keywords, and abstracts. Thereafter, 133 papers were excluded because either 1. the central issue was irrelevant to language or vocabulary acquisition, or 2 . the focus of the content was different. Finally, 17 papers were left for synthesizing and systematic literature review. In the following diagram, the process of selection is illustrated.
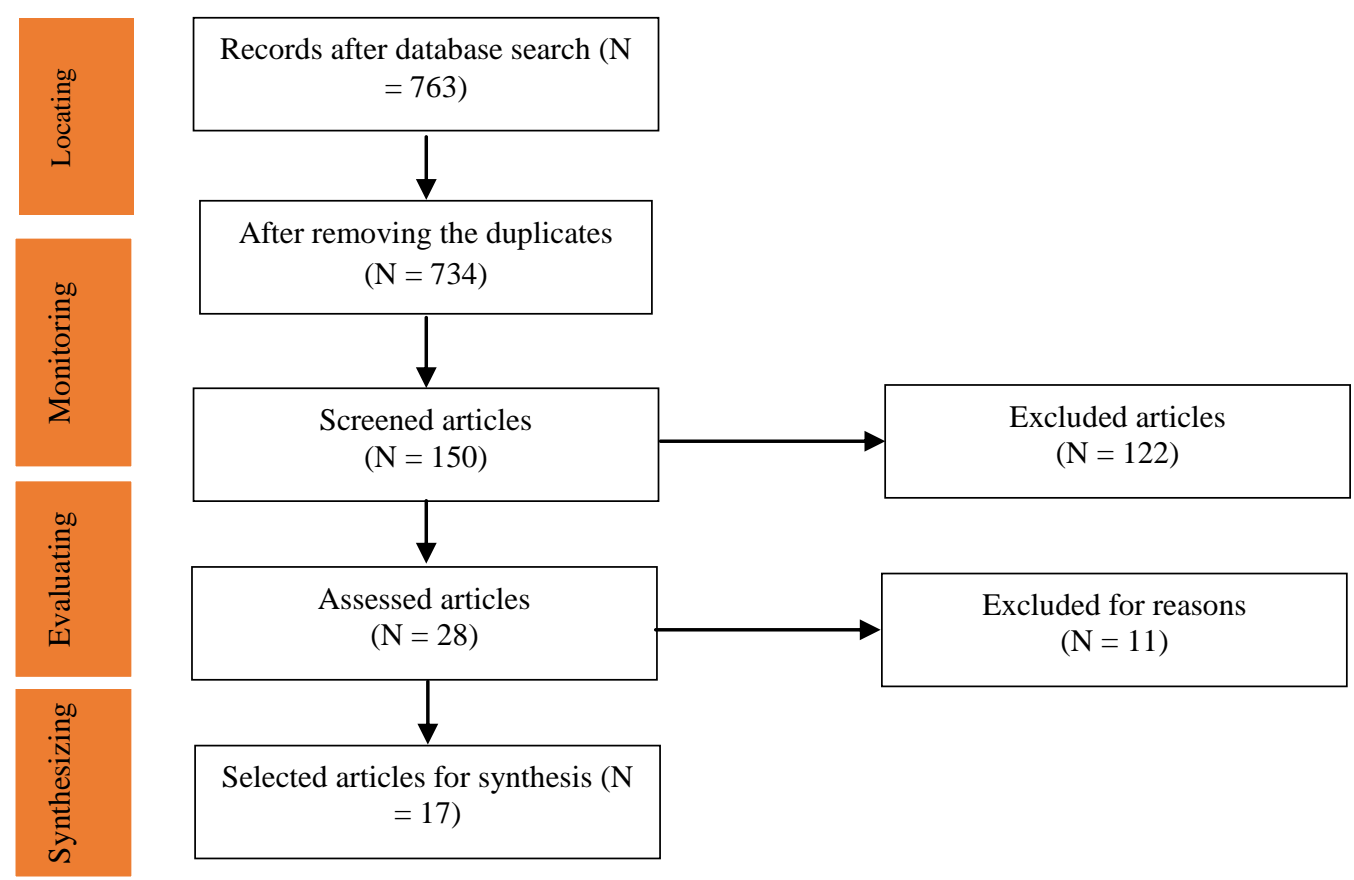

Figure 1: PRISMA flow diagram for locating the literature

\section{ORGANIZING THE LITERATURE AND RESULTS}

Based on the Grounded Theory approach (Corbin \& Strauss, 1990), the papers were analyzed and synthesized. In an attempt to synthesize the papers, themes were found that were grouped into broader themes. Then, emerged themes were organized in a list, and the paper was marked by a code. After synthesizing all papers, themes were categorized into the broader groups according to their relevance. After synthesizing the papers carefully, seven themes emerged. Sorting by the frequency of occurrence, themes were: 1. Motivation, 2. Repetition, 3. Feedback, 4. Virtual World, 5. Dual Encoding, 6. Interactivity, and 7. Instantiation. Motivation was the most recurring theme, and instantiation was the least recurring theme. In the next section, how the emerged themes are contributing to vocabulary acquisition and why DGBVL tasks can enhance vocabulary learning effectively is discussed.

\section{DISCUSSION}

In this paper, why DGBVL tasks can effectively enhance vocabulary learning was investigated. Seven factors were found that have been reported and indicated frequently in the available DGBVL literature. These factors have been mentioned widely as contributive factors to the effectiveness of DGBVL tasks. In what follows, each theme is explained, and it is discuss how each factor can boost vocabulary learning.

\section{A. Digital Games Provide a High Level of Motivation}


Motivation has been widely embraced by both practitioners and researchers as a critical determinant of success in language learning, and this belief is strongly supported by a wide range of studies on L2 motivation [...] hence, it is logical to assume that motivation also facilitates vocabulary learning. (Tseng \& Schmitt, 2008, p. 385)

"The motivated individual is goal-directed, expends effort, is persistent, is attentive, has desires, exhibits positive effect, is aroused, has expectancies, demonstrates self-confidence (self-efficacy), and has reasons (motives)" (Gardner, 2007, p. 10). Motivation is arousing interest and keeping that interest at a certain level when putting any effort into gaining a certain goal, for making that effort pleasant, constant, and continuous (Tseng \& Schmitt, 2008). Motivation contains three phases: Pre-actional, actional, and post-actional. In the pre-actional phase, motivation is generated; in the actional phase, the generated motivation is protected and regulated, and in the post-actional phase, the effect of generated motivation on the processes that were run for reaching a certain goal will be evaluated. Positive outcomes of evaluation, in this phase, guarantee the willingness to continue and put much effort into the task (Tseng \& Schmitt, 2008).

Digital games are motivating and engaging (Jaipal \& Figg, 2009). Researchers have mentioned different sources of motivation in digital games. For instance, Garris, Ahler, and Driskell (2002) indicated that elements like control as well as confidence, in digital games, can escalate motivation and result in desirable learning. Pivec, Dziabenko, and Schinnerl (2003) discussed that interactivity, rules, goals, challenge, risk, fantasy, curiosity, and control increase learners' motivation so high that keeps them continuously active in a task. Also, Dickey (2006, as cited in Dondlinger, 2007) mentioned that contextual elements, in digital games, like the challenge, fantasy, and curiosity would promote intrinsic motivation.

Digital game-enhanced motivation is reported to be beneficial in vocabulary learning. For example, Turgut and Irgin (2009, p. 763) mentioned that "for participants, understanding the information presented in both written and oral dialogues had importance motivating them to learn unknown words and focusing on characters' speech in the game to win the game". Regarding the three phases of motivation, we can infer that digital games may continuously keep the learners' motivation high throughout the three phases. Hence, obtaining and understanding the information in the digital games and their importance for the gamer can generate motivation (Phase 1). Elements like interactivity, rules, goals, challenge, risk, fantasy, curiosity, and control may generate motivation. Digital games can sustain motivation distinctively by heightening a sense of winning in learners (Phase 2). Feeling like this, everything in the games, like dialogues, texts, and pictures, looks very important for a learner (Turgut \& Irgin, 2009). Finally, digital games motivate the gamer to put more effort into the game by providing feedbacks like scores, levels passed, powers that are obtained, etc. (Phase 3).

In practice, Jasso (2012) compared the performance of learners who experienced learning some target words through a DGBVL task to participants who learned the same target words through the text-and-drill tasks. She found that the DGBVL task enhanced vocabulary acquisition more effectively than the text-and-drill did. She concluded that the element of motivation contributed effectively to the effectiveness of the DGBVL task. Also, she observed that the experimental group participants were more interested in the task because they felt that it was going to be fun. Moreover, they were curious about playing a digital game for learning vocabulary items as a classroom activity (Phase 1). She explained that when the learners with the DGBVL task experienced their freedom in interaction and manipulation, they dared to engage deeper with the game and the task. Also, they attempted to make jokes out of it by designing their character funny and daring to explore the items that were not planned for the study. Most of their attempts were to design a better and funnier character than other learners (Phase 2). Jasso (2012) also indicated that follow-up discussions increased the learners' motivation and it might have helped vocabulary learning. The follow-up discussions that centered around the digital game and the DGBVL task motivated the gamers to continue the game and put more effort into the task. In the follow-up discussions, learners might have learned more about the digital game. This might sustain their motivation level long enough to persuade them into obtaining a higher profile, score, etc. than others to flaunt in the next discussions (Phase 3).

Due to the success of the DGBVL task in providing the three phases of motivation, it can be inferred why DGBVL tasks can be effective in vocabulary learning.

\section{B. Digital Games Provide Different Types of Repetition}

"L1 and L2 incidental learning studies have found that the number of times an unknown word is met in context affects whether its meaning will be acquired" (Webb, 2007, p. 46). "Repetition is essential for vocabulary learning because there is so much to know about each word that one exposure is not sufficient to gain this information". Hence, repetition deepens both the quality and the quantity of word knowledge (Nation, 2001, pp. 74-76).

Digital games can provide learners with enough repetition and frequencies of occurrences. For example, in Abu Bakr and Nosratirad's (2013) study, participants mentioned that the frequency of exposure to the target words in the SIMS III, helped them learn vocabulary items effectively. Yip and Kuwan (2006) discussed that motivation and especially the sense of winning would generate repetition in digital games. They explained that because gamers want to break theirs or others' scores or they love the story, content, gameplay, etc., they replay it over and over again. Consequently, the frequency of exposure with the same vocabulary items increases and results in learning vocabulary items effectively.

"Computer game provides them with a learning environment that allows them to use the same words but in a different environment many times. Frequent and repeated contact with new English words in the game appeared to make learning vocabulary easier for them, as they had the chance to review what they had learned before. In other words, frequently exposing them to new words enables them to remember the meaning of the words. Therefore, English words will 
gradually accumulate as they play the game. The game also provides them with a learning environment that encourages learners to further understand the words by giving different situations using the same word. Not only do learners learn new words, but they are also able to remember and use them in real life situations". (Abu Bakr and Nosratirad, 2013, p. 240)

\section{Digital Games Supply Gamers with Various Types of Feedback}

In the literature on [second language acquisition] SLA, the kind of feedback that is directed towards learning is generally known as "corrective feedback" (CF) or "negative feedback". CF refers to all responses to learners' erroneous L2 utterances, and it may include an indication that an error has been made, can present the correct form or metalinguistic information about the nature of the error, or it may combine these various forms of information. (Cornillie, Clarebout, \& Desmet, 2012, p. 257)

Numerous studies report positive effects of corrective feedback on learning different aspects of language in SLA literature (Long, Inagaki, \& Ortega, 1998; Ferreira, Moore, \& Mellish, 2007).

By entering computers into language classrooms, integration of feedback as an inevitable part of computer-assisted language learning (CALL) revealed new perspectives to the researchers. There was a common idea that computer-generated feedback would assist language learning more effective than traditional classroom feedback. Many studies have also studied the feasibility of this idea. For example, Neri, Cucchiarini, and Strik (2008) found that automatic speech recognition-based feedback improved the pronunciation of language learners effectively. Moreover, Murphy (2010) found that learners who had received elaborative feedbacks through the web outperformed learners who had follow-up exercises in the classroom, in a reading comprehension test.

In vocabulary learning, computers were also more successful in providing feedback. Allum (2004) introduced CALL as one of the most effective methods of introducing new vocabulary items because

CALL can provide both the opportunities for productive recall and the feedback to motivate repeated efforts to produce new items. The latter capability appears to give CALL some advantages over paper-based exercises, in particular when such learning is done out of class time without immediate teacher feedback. (Allum, 2004, p. 488)

He explained that a distinctive feature, like immediate feedback, would make CALL an influential option for use in vocabulary teaching because immediate feedback elevates motivation and encourages learners to invest more effort in learning and producing new vocabulary items.

In the available DGBVL literature, feedback has been indicated as an important factor for vocabulary learning. But the type and aim of feedbacks are distinctive in digital games. For example, in commercial games, feedback provides information on how well the gamers have performed during their gameplay. Freitas and Maharag (2011), among many other features of digital games, emphasized on the role of feedback in digital games. They explain that the presence of various types of feedback such as evaluative, interpretive, supportive, probing, and understanding feedback in digital games help in understanding how digital games may assist learning. Feedbacks in digital games, although different, have some advantages. First, in digital games, feedback is the outcome of trial and error for solving problems (kiili, 2005). In other words, if a problem is not solved, a game does not proceed, and it indicates that the gamer's strategy or effort has failed. Hence, immediate feedback in the games acts like teachers. Second, feedback in digital games corresponds with focus on meaning in SLA because "it is connected to the representation of the game's world or theme" (Cornillie, Clarebout, \& Desmet, 2012, p. 260). Third, unlike findings in the SLA literature that report corrective feedback can be harmful because it reduces motivation (Truscott, 1996, as mentioned in Cornillie, Clarebout, \& Desmet, 2012), feedback, in digital games, increases motivation (Cornillie, Clarebout, \& Desmet, 2012). Finally, feedback provided in both traditional classrooms and CALL may be neglected by the user (Murphy, 2010), but in digital games, feedbacks must be observed and noticed carefully; otherwise the game does not proceed. Cornillie, Clarebout, and Desmet, (2012) explored the role of feedback in an immersive game for English pragmatics. They found that feedback in digital games plays a crucial role in language and vocabulary learning.

\section{Digital Games Provide Authentic Contexts for Learning in Their Virtual Worlds}

The superiority of authentic material over a contrived version for language learning has been reported widely. "The great advantage of natural, idiomatic texts over artificial methods or series is that they do justice to every feature of the language" (Sweet, 1899, as cited in Gilmore, 2007). Authenticity is every utterance that is produced by a real speaker/writer for any real audience, in every language community and in every linguistic context, which conveys a real message (Gilmore, 2007, p. 98).

According to McDonough (2002), traditional classes duplicate the context that causes de-authentication or a decrease in providing useful context for learning. The main reason is that traditional textbooks and materials are contrived, unnatural, and do not fulfill learners' communicative needs (Gilmore, 2007). To overcome this problem, "the first step is to present language solidly contextualized and to sensitize learners to the ways in which the discourse reflects its context. [this could be done by] authentic material, particularly audio-visual ones, [because] they offer a much richer source of input for learners" (2007, p. 103).

According to Gee, et al., (2005), digital games are powerful virtual world-based learning tools. Virtual worlds create contexts like real worlds by their audio-visual components. In virtual worlds, learners can control the real world virtually. Reflecting on Gilmore's suggestion, digital games can create an authentic context for learning through their virtual worlds 
and audio-visual components. In other words, learning happens in a real-life-like context. Combining pictures, audios, videos, and graphics, a virtual world can generate a rich context for the gamer to learn almost any subject and skill. In a virtual world, language learning can be considered as learning as a second language because both language and culture are visualized for the learner. In learning as a second language context, the rate of vocabulary learning increases (Nation, 2001) because the frequency of exposure is high. Hence, language learners might learn more vocabulary items through DGBVL tasks than other vocabulary learning tasks.

Milton (2010) mentions a commercial simulation game, called Second Life by Linden Lab (2003), where gamers can participate in an international virtual metropolitan city. He believes that because the game can provide a lot of opportunities for exposure to authentic language and interaction, it can be advantageous for language learning. According to Milton (2010), to be a part of the virtual society, a gamer needs to interact with others, for example, a bank teller in a virtual bank. Therefore, unlike traditional classrooms, providing authenticity can become easier and more feasible in digital games, which may result in a higher rate of vocabulary acquisition.

\section{E. Digital Games Provide a Rich Context for Dual Encoding}

"Dual Encoding" is storing a concept in mind both linguistically and visually (Paivio \& Desrochers, 1981; as cited in Nation, 2001). In dual coding theory, cognition is composed of two distinct subsystems. A verbal system that deals with language directly, and a nonverbal or imagery system that processes nonlinguistic objects and events. Hence, cognition is the storage of concepts processed and organized by those two subsystems (Sadoski, 2005; Paivio, 2006). Regarding the dual coding theory, both nonverbal and verbal codes can affect vocabulary recall. They can leave a dual verbal-nonverbal memory trace by connecting, for example, an image to a concrete noun (Paivio, 2006, p.4). Dual encoding can also assist in connecting newly learned written forms to previously learned speech forms (Sadoski, 2005, p. 223). Paivio (2006) reports the positive effect of dual encoding techniques such as image-word connection on vocabulary learning, and successful word recall. Mayer (1999, as cited in Paivio, 2006, p. 11) emphasizes the role of dual encoding and proposes the utilization of multimedia in learning because in multimedia contexts, words and pictures are used more than words alone.

Nation (2001) emphasized the role of dual encoding in creating successful vocabulary learning tasks. "DCT [dual coding theory] can account for some of the most effective vocabulary learning strategies that have been devised for both sight word learning and the learning of meaningful vocabulary" (Sadoski, 2005, p. 233). Sadoski (2005) reports the effectiveness of the vocabulary learning tasks using dual coding techniques on learning new vocabulary items. Kim and Gilman (2008) also evaluated the effect of the text, audio, and graphics on vocabulary learning. Their findings support previous findings and indicate that participants who learned vocabulary items aided by visual texts and graphics, excelled in both retrieving and recalling the word forms and their meanings.

Digital games can implement dual coding techniques effectively. By using audios, videos, pictures, graphics, etc. in their virtual worlds, digital games can encourage learners to connect both forms and meanings successfully. Therefore, learning vocabulary through DGBVL tasks can be productive because "when a graphic display is used with the semantically related vocabulary, results are usually effective" (Sadoski, 2005, p. 233).

Vahdat and Rasti-Behbahani (2013) found that one of the reasons for the success of the DGBVL task in their study was the existence of graphical elements like pictures and icons. In other words, during the DGBVL task completion, learners not only were provided with the text and definitions but also were supported by images and graphical representation of the words. It enhanced vocabulary learning effectively.

\section{F. Digital Games Provide a High Degree of Interactivity, Manipulation, and Control over Content}

"Interactivity, the extent to which users can participate in modifying the form and content of a mediated environment in real time, is a defining characteristic of video games [...] while television is something you watch, a video game is something you do" ( deHaan, Reed, \& Kuwada, 2010, p. 75). According to Gee (2003), digital games follow the insider principle, where learners have the right to manipulate, modify, and customize from the very beginning and during the process because they are insiders. Since learners can manipulate, they have a higher degree of control and interactivity with tasks in digital games.

Due to features, such as control, manipulation, and interactivity, learners can have a high chance for vocabulary learning because "Control in games enables players to determine and predict the outcome of actions or events" (Huang \& Johnson, 2009, p. 5), and also players can generate and test their hypotheses through trial and error as well as immediate feedback. Learners' interactivity with the game results in either progress or failure in the game and consequently, in learning. For example, a successful interaction can cause the connection of meaning to a proper form in a learner's mind. Therefore, elements of control, manipulation, and interactivity in digital games, may support vocabulary learning. Duly, guessing from the context, for example, may never fail or lead to false learning because inappropriate interactions do not help a game to progress. Mohsen (2016) found that digital game players, who had a high degree of interactivity with a surgery digital game, learned target vocabulary items more effectively than the control group, who just watched the video game and did not interact with it.

\section{G. Digital Games Nourish the Gamers by Rich Instantiations for Words}


For Anderson, et al, (1976), a word has more than one meaning. Meanings are collected during exposure to the words in different contexts. Hence, more exposures to a word in various contexts may lead to the collection of more meanings for the word and also a deeper understanding of that word. They discuss that meanings will be collected during the process of instantiation (ibid.). "If the context is rich and if the message is processed deeply, a noun may be identified with a single real or imagined thing. This process will be called instantiation" (Anderson et al., 1976). In other words, "instantiation involves recalling or experiencing a particular instance or example of the meaning of a word. For example, we see an actual ball when we meet the word form ball" (Anderson, Stevens, Shifrin, \& Osborn, 1978, p. 70, as cited in Nation, 2001).

Instantiation is very important in sentence comprehension, and different instantiations take place based on context variety (Oakhill, 1983). Therefore, the importance of instantiation in learning and understanding linguistic messages in both oral and textual formats is undeniable. Also, Nation (2001) emphasizes that instantiation is noticeably effective in vocabulary learning.

Digital games are very resourceful in providing instantiations. Zheng, Bischoff, and Gilliland (2015), for example, were trying to learn how a language is learned while gamers interact with Massively Multiplayer Online Role-Playing Games (MMORPG). They observed the role of instantiation in learning new words in digital games. A gamer who was trying to understand what the verb to repop meant, despite his co-player's rich description, learned its meaning when an enemy character appeared suddenly in front of them in the game. It was an instantiation of the verb to repop.

"Learning the word "repop" here might not have happened at all without that very thing occurring at that moment. As an expert, Mediziner [the native English spraker] could have explained the concept of repop to Conan [the Non-native Speaker] before undertaking the quest, but we suspect that even with a definition, repopping likely still does not make much sense to any non-MMOG players who are reading" (Zheng, Bischoff, \& Gilliland, 2015, p. 785).

\section{CONCLUSION}

In this paper, why digital games can be advantageous for vocabulary learning was discussed based on the available DGBVL literature. The presence of factors such as motivation, authenticity, instantiation, repetition, interactivity, control, and dual encoding in digital games can supply learners with a rich context that offers many opportunities for effective vocabulary learning. Moreover, components of the virtual world, such as gameplay and audiovisual components, can enhance the effect of those factors.

The outcome of this study may assist prospective researchers to look deeper into digital games and DGBVL tasks. Also, it may help those who want to migrate from "what" to "how" questions in DGBVL studies. Finally, it is worth mentioning that although emerged themes are frequently discussed in the available DGBVL literature, they are not empirically studied. Hence, prospective researchers can consider the effect of those factors in their future studies.

\section{REFERENCES}

[1] Alias, N., Rosman, F., Rahman, M. N. A., \& Dewitt, D. (2015). The potential of video game in Malay language learning for foreign students in a public higher education institution. Procedia-Social and Behavioral Sciences, 176, 1020-1027.

[2] Allum, P. (2004). Evaluation of CALL: Initial vocabulary learning. ReCALL, 16(02), 488-501.

[3] Anderson, R. C., Pichert, J. W., Goetz, E. T., Schallert, D. L., Stevens, K. V., \& Trollip, S. R. (1976). Instantiation of general terms. Journal of Verbal Learning and Verbal Behavior, 15(6), 667-679.

[4] Anderson, R. C., Stevens, K. C., Shifrin, Z., \& Osborn, J. H. (1978). Instantiation of word meanings in children. Journal of Literacy Research, 10(2), 149-157.

[5] Bakar, N. A., \& Nosratirad, E. (2013). Sustaining vocabulary acquisition through computer game: A case study. Asian Social Science, 9(5), 235-242.

[6] Carter, R. (1998). Vocabulary: Applied linguistics perspective. London: Routledge.

[7] Chian-Wen, K. A. O. (2014). The Effects of Digital Game-based Learning Task in English as a Foreign Language Contexts: A Meta-analysis. Education Journal, 42(2), 113-141.

[8] Chen, M. H., Tseng, W. T., \& Hsiao, T. Y. (2018). The effectiveness of digital game-based vocabulary learning: A framework-based view of meta-analysis. British Journal of Educational Technology, 49(1), 69-77.

[9] Corbin, J., \& Strauss, A. (1990). Grounded theory research: Procedures, canons and evaluative criteria. Zeitschrift für Soziologie, 19(6), 418-427.

[10] Cornillie, F., Clarebout, G., \& Desmet, P. (2012). Between learning and playing? Exploring learners' perceptions of corrective feedback in an immersive game for English pragmatics. ReCALL, 24(03), 257-278.

[11] Creswell, J. W. (2002). Educational research: Planning, conducting, and evaluating quantitative (pp. 146-166). Upper Saddle River, NJ: Prentice Hall.

[12] De Freitas, S., \& Maharg, P. (Eds.). (2011). Digital games and learning. Bloomsbury Publishing.

[13] deHaan, J., Reed, W. M., \& Kuwada, K. (2010). The effect of interactivity with a music video game on second language vocabulary recall. Language Learning \& Technology 14(2), 74-94.

[14] Dondlinger, M. J. (2007). Educational video game design: A review of the literature. Journal of applied educational technology, 4(1), 21-31.

[15] Ferreira, A., Moore, J. D., \& Mellish, C. (2007). A study of feedback strategies in foreign language classrooms and tutorials with implications for intelligent computer-assisted language learning systems. International Journal of Artificial Intelligence in Education, 17(4), 389-422. 
[16] Figg, C., \& Jaipal, K. (2009). Using video games in science instruction: Pedagogical, social, and concept-related aspects. Journal of Canadian Journal of Science, Mathematics and Technology Education, 9(2), 117-134.

[17] Fotouhi-Ghazvini, F., Earnshaw, R. A., Robison, D., \& Excell, P. S. (2009). The MOBO City: A Mobile Game Package for Technical Language Learning. iJIM, 3(2), 19-24.

[18] Gardner, R. C. (2007). Motivation and second language acquisition. Porta Linguarium, 8, 9-20.

[19] Garris, R., Ahlers, R., \& Driskell, J. E. (2002). Games, motivation, and learning: A research and practice model. Simulation \& gaming, 33(4), 441-467.

[20] Gee, J. P. (2003). What video games have to teach us about learning and literacy. London: Palgrave Macmillan.

[21] Gee, J. P., Halverson, R., Shaffer, D. W., \& Squire, K. R. (2005). Video games and future of learning. Retrieved September 7 , 2009, from http://www.wcer.wisc.edu/publications /workingpapers/working_paper_no_2005_4.

[22] Gilmore, A. (2007). Authentic materials and authenticity in foreign language learning. Language teaching, 40(02), 97-118.

[23] Harzing, A. W. (2010). The publish or perish book. Tarma Software Research Pty Limited.

[24] Huang, W. D., \& Johnson, T. (2009). Instructional game design using cognitive load theory. Handbook of research on effective gaming in education, 3, 1143-1165.

[25] Hung, K. H. (2011). The design and development of an education-designed massively multiplayer online role-playing game (edd mmorpg) for young Taiwanese mandarin-speaking learners learning English vocabulary words (Unpublished Doctoral dissertation). Teachers College, Columbia University.

[26] Jasso, P. R. (2012). A non-academic computer video game: Its effect on vocabulary acquisition in the EFL classroom (Unpublished Doctoral dissertation). Syracuse University.

[27] Kang, S. H. (1995). The effects of a context-embedded approach to second-language vocabulary learning. System, 23(1), 43-55.

[28] Kiili, K. (2005) Digital game-based learning: Towards an experiential gaming model. The Internet and Higher Education, 8(1): $13-24$.

[29] Kim, D., \& Gilman, D. A. (2008). Effects of Text, Audio, and Graphic Aids in Multimedia Instruction for Vocabulary Learning. Educational Technology \& Society, 11(3), 114-126.

[30] Kirriemuir, J. (2002). The relevance of video games and gaming consoles to the higher and further education learning experience. Techwatch report TSW, 2.

[31] Liberati, A., Altman, D. G., Tetzlaff, J., Mulrow, C., Gøtzsche, P. C., Ioannidis, J. P., \& Moher, D. (2009). The PRISMA statement for reporting systematic reviews and meta-analyses of studies that evaluate health care interventions: explanation and elaboration. PLoS medicine, 6(7), e1000100.

[32] Long, M. H., Inagaki, S., \& Ortega, L. (1998). The role of implicit negative feedback in SLA: Models and recasts in Japanese and Spanish. The modern language journal, 82(3), 357-371.

[33] McDonough, S. (2002). Applied linguistics in language education. London: Arnold.

[34] Milton, J. (2010). Second Language Acquisition via Second Life. In Chapelle, C., A. (Eds.2), The Encyclopedia of Applied Linguistics (pp. 1-9). Blacwell Publishing Ltd. DOI: 10.1002/9781405198431.wbeal1318.

[35] Mohsen, M. A. (2016). The use of computer-based simulation to aid comprehension and incidental vocabulary learning. Journal of Educational Computing Research, 54(6), 863-884.

[36] Murphy, P. (2010). Web-based collaborative reading exercises for learners in remote locations: the effects of computer-mediated feedback and interaction via computer-mediated communication. ReCALL, 22(02), 112-134.

[37] Nation, I. S. P. (2001). Learning vocabulary in another language. Cambridge: Cambridge University Press.

[38] Neri, A., Cucchiarini, C., \& Strik, H. (2008). The effectiveness of computer-based speech corrective feedback for improving segmental quality in L2 Dutch. ReCALL, 20(02), 225-243.

[39] Oakhill, J. (1983). Instantiation in skilled and less skilled comprehenders. Quarterly Journal of Experimental Psychology, 35(3), 441-450.

[40] Paivio, A. (2006). Dual coding theory and education. Ponencia presentada en: Pathways to Literacy Achievement for High Poverty Children, University of Michigan. Recuperado de: http://www. umich. edu/ rdytolrn/pathwaysconference/pathways. html. Retrieved 28, 04, 2019.

[41] Pivec, M., Dziabenko, O., \& Schinnerl, I. (2003, July). Aspects of game-based learning. In 3rd International Conference on Knowledge Management, Graz, Austria (pp. 216-225).

[42] Rankin, Y., Gold, R., \& Gooch, B. (2006). 3D role-playing games as language learning tools. In Proceedings of EuroGraphics (Vol. 25, No. 3, pp. 211-225).

[43] Sadoski, M. (2005). A dual coding view of vocabulary learning. Reading \& Writing Quarterly, 21(3), 221-238.

[44] Tseng, W. T., \& Schmitt, N. (2008). Toward a model of motivated vocabulary learning: A structural equation modeling approach. Language Learning, 58(2), 357-400.

[45] Turgut, Y., \& Irgin, P. (2009). Young learners' language learning via computer games. Procedia-Social and Behavioral Sciences, 1(1), 760-764.

[46] Vahdat, S., \& Rasti-Behbahani, A. (2013). The effect of video games on Iranian EFL learners' vocabulary learning. Reading Matrix, 13(1), 61-71.

[47] Webb, S. (2007). The effects of repetition on vocabulary knowledge. Applied linguistics, 28(1), 46-65.

[48] Yip, F. W., \& Kwan, A. C. (2006). Online vocabulary games as a tool for teaching and learning English vocabulary. Educational media international, 43(3), 233-249.

[49] Zheng, D., Bischoff, M., \& Gilliland, B. (2015). Vocabulary learning in massively multiplayer online games: context and action before words. Educational Technology Research and Development, 63(5), 771-790.

[50] Zou, D., Huang, Y., \& Xie, H. (2019). Digital game-based vocabulary learning: where are we and where are we going?. Computer Assisted Language Learning, 32(8), 1-27. DOI: 10.1080/09588221.2019.1640745. 
Amin Rasti-Behbahani is a Ph.D. researcher at the University of Jyvaskyla, Finland. He is currently working on his doctoral thesis. His area of research interest is vocabulary acquisition and digital game-based learning. Amin is reachable by email: amin.rasti@outlook.com 